\title{
Social vulnerability assessment of flood risk using GIS-based multicriteria decision analysis. A case study of Vila Nova de Gaia (Portugal)
}

\author{
PAULO FERNANDEZ $* \dagger$, SANDRA MOURATO $\ddagger$ and \\ MADALENA MOREIRA $§$ \\ †ICAAM - Instituto de Ciências Agrárias e Ambientais Mediterrânicas, Universidade de \\ Évora, Pólo da Mitra, Ap. 94, 7002-554, Évora, Portugal e Instituto Politécnico de \\ Castelo Branco - Escola Superior Agrária, Portugal \\ ‡ICAAM - Instituto de Ciências Agrárias e Ambientais Mediterrânicas, Universidade de \\ Évora, Pólo da Mitra, Ap. 94, 7002-554, Évora, Portugal e Instituto Politécnico \\ de Leiria - Escola Superior de Tecnologia e Gestão, Portugal \\ $\S$ Departamento de Engenharia Rural, ICAAM - Instituto de Ciências Agrárias e \\ Ambientais Mediterrânicas, Universidade de Évora, Pólo da Mitra, Ap. 94, 7002-554 \\ Évora, Portugal
}

(Received 8 April 2014; accepted 12 May 2015)

\begin{abstract}
Over the last decade, flood disasters have affected millions of people and caused massive economic losses. Social vulnerability assessment uses a combination of several factors to represent a population's differential access to resources and its ability to cope with and respond to hazards. In this paper, social vulnerability assessment to flood risk was applied to the third most populous Portuguese municipality. The study was developed at the neighbourhood level, allowing for social vulnerability analysis at inter civil parish, intra civil parish, and municipality scales. A geographic information system-based multicriteria decision analysis (GIS-MCDA) was applied to social vulnerability and allows for an increased understanding and improved monitoring of social vulnerability over space, identifying 'hot spots' that require adaptation policies. Mafamude, Oliveira do Douro, Vila Nova de Gaia, and Avintes civil parishes display the greatest vulnerability to flooding. According to the most pessimistic scenario $57 \%-68 \%$ of the area of these civil parishes is classed at a high or very high level of social vulnerability. The GIS-MCDA helps to assess what and who is at risk, and where targeted impact-reduction strategies should be implemented. The results demonstrate the importance of an urban-scale approach instead of a river basin scale to urban flood risk management plans.
\end{abstract}

\section{Introduction}

Floods are associated with extreme precipitation events and have a significant influence on society (Lenderink \& van Meijgaard 2008). Flood events are now reported more than ever before due to the increasing spread of human settlement and development activities in urbanized areas. Extreme precipitation variability and climate uncertainty have been greater in recent years (Costa \& Soares 2009). Climate model

*Corresponding author. Email: palex@ipcb.pt 